\title{
Why nasal airways experience drying during nasal-applied continuous positive airway pressure (n-CPAP) therapy
}

\section{AUT BIODESIGN LAB Dr David White} AUT BioDesign Lab

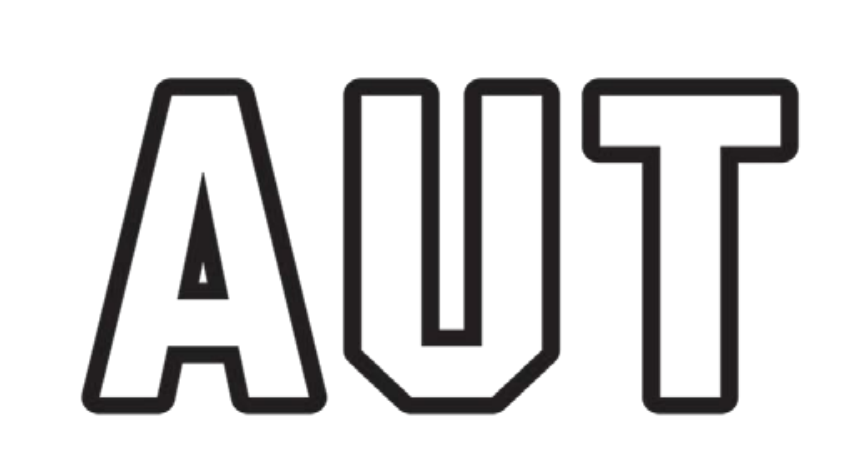

\& KiwiNet
Dr Jim Bartley

Department of Surgery

University of Auckland
THE UNIVERSITY OF AUCKLAND

\section{Introduction}

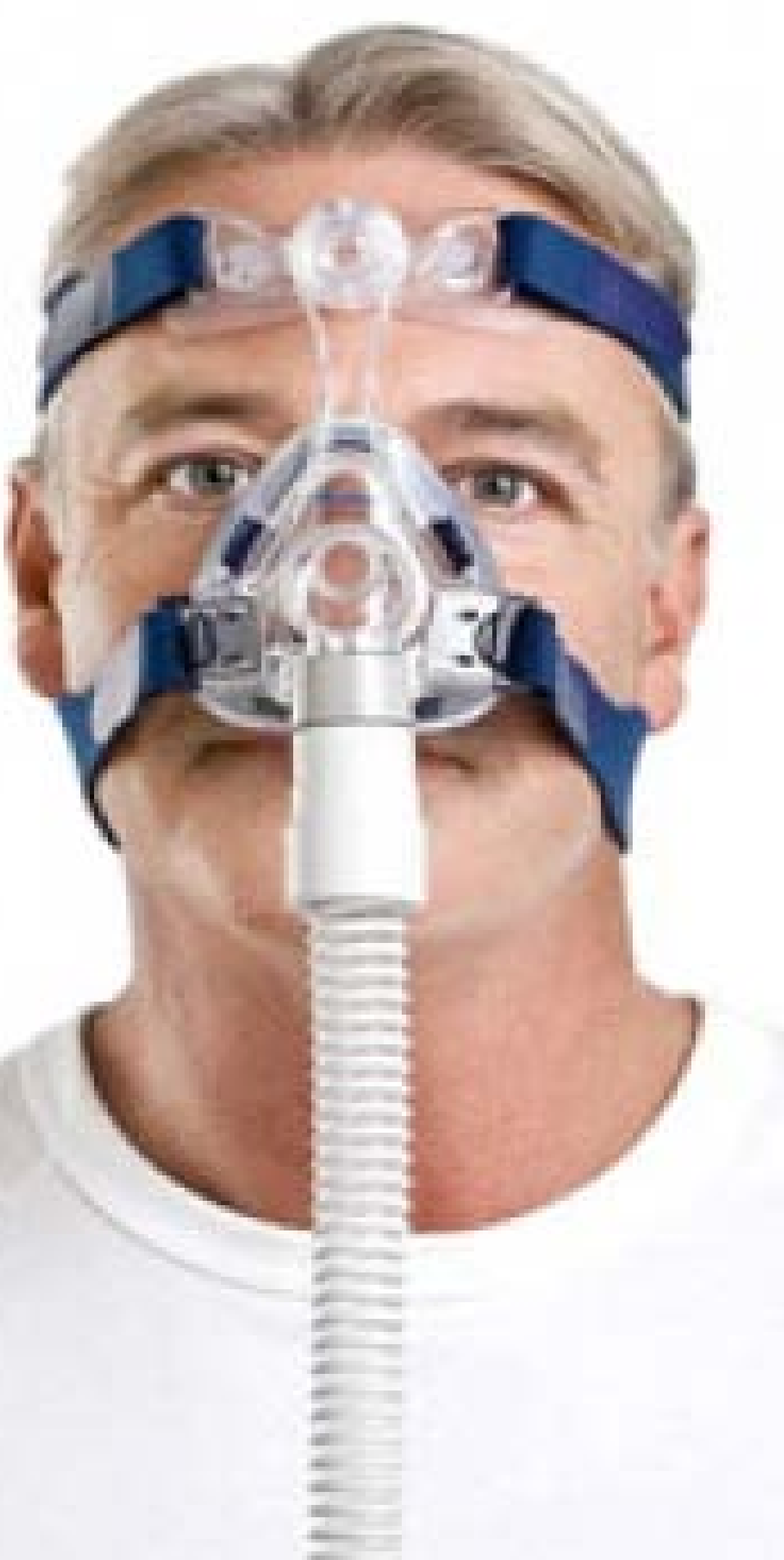

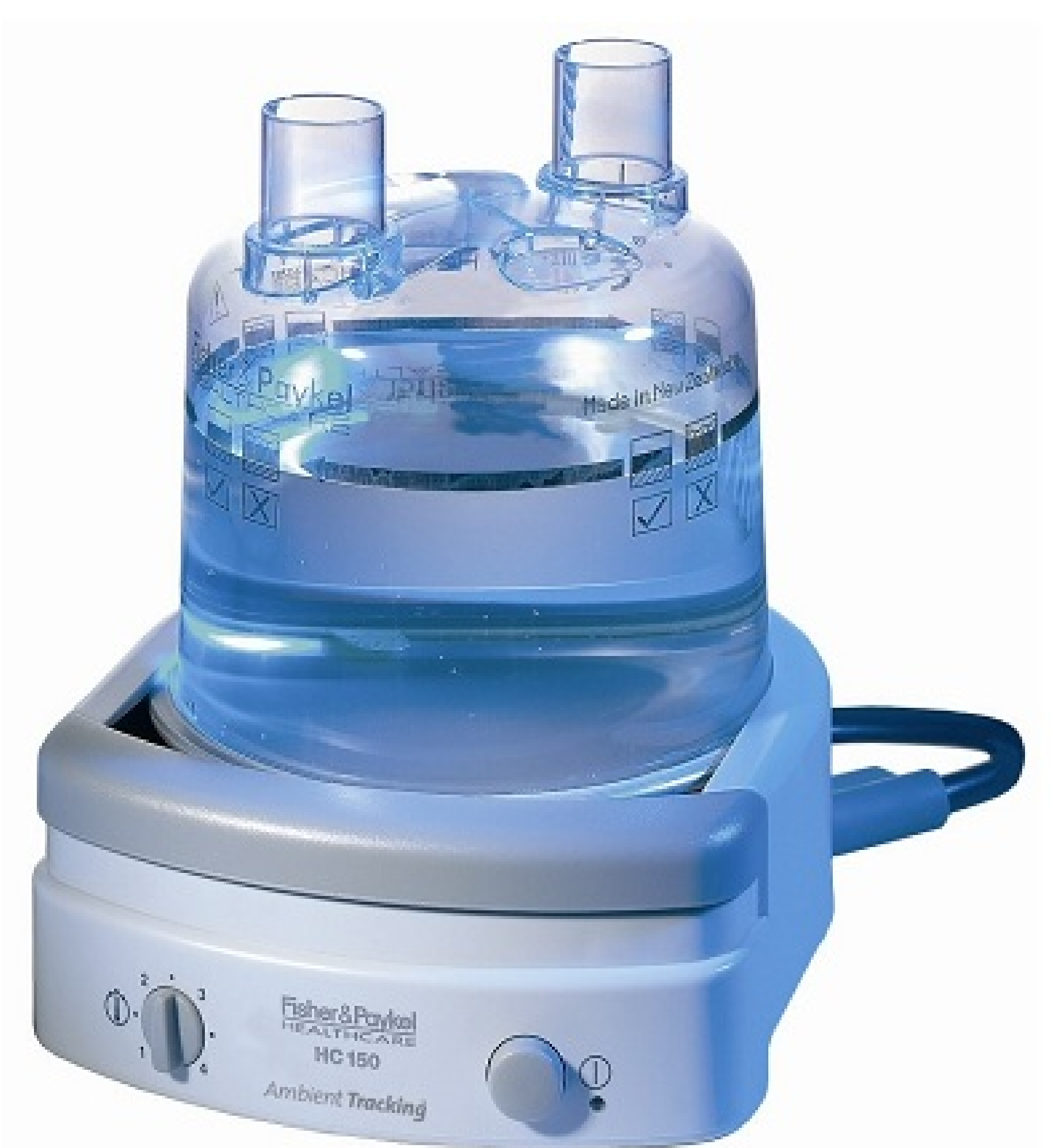

Since its introduction over thirty years ago, nasal-applied continuous positive air pressure (n-CPAP) therapy users have commonly reported symptoms associated with upper airway drying. The ability of the human nose to humidify inhaled ambient air seems impaired during n-CPAP breathing. Despite n-CPAP therapy being highly efficacious in resolving upper airway obstruction, user discomfort caused by airway drying is associated with poor treatment compliance. Supplementary humidification relieves these symptoms however the causes(s) of airway drying remains speculative, and whether supplementary humidification is a total solution has not been determined.

\section{Functional Purpose of the Nasal Cycle}

During ambient breathing one nasal airway normally conducts the majority of airflow for a period of time before swapping sides in what is termed the 'nasal cycle'. This variation enables the airway surface liquid (ASL) in one nasal passageway to remain fully hydrated, facilitating effective mucociliary transport, while the other side experiences ASL dehydration as a result of it carrying out the bulk of air-conditioning duty. Change in the status of the nasal cycle enables each side of the nose to experience periods of tissue rest and recovery [1].

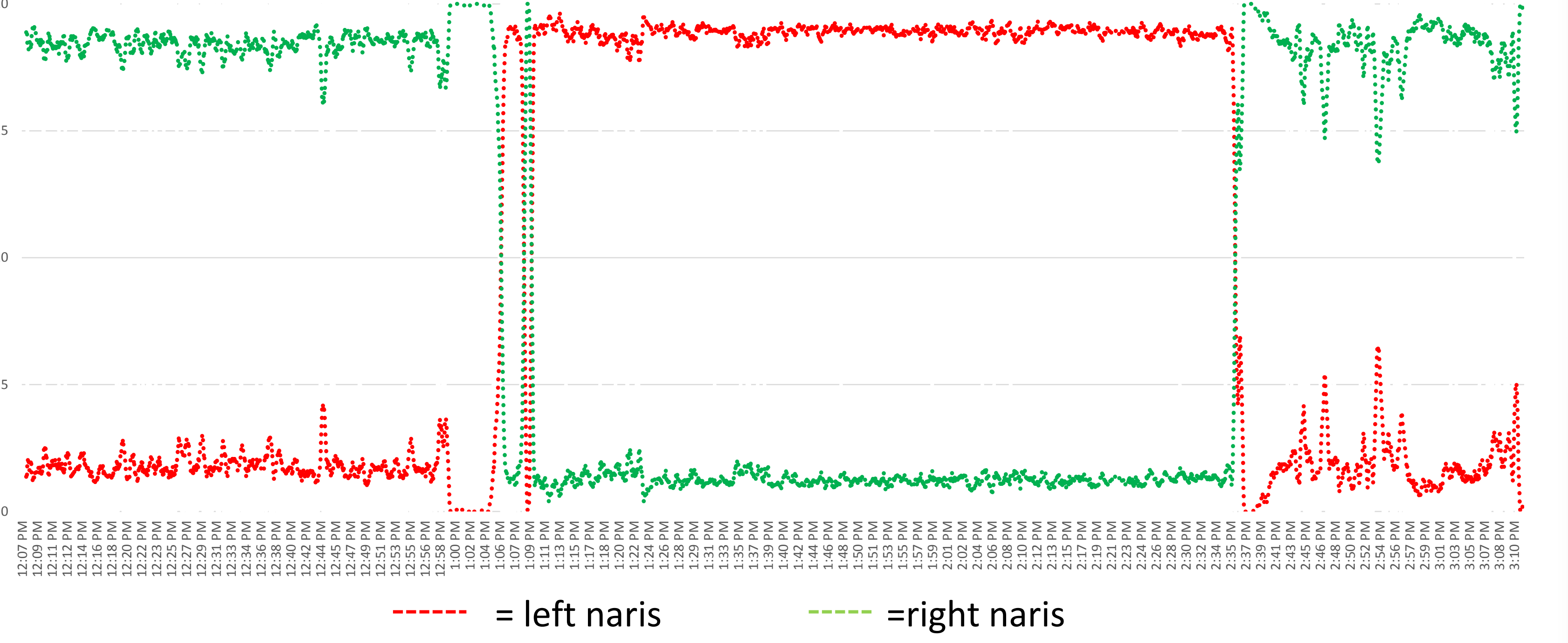

Figure 1: Measured in-vivo inter-nasal airflow during ambient breathing.

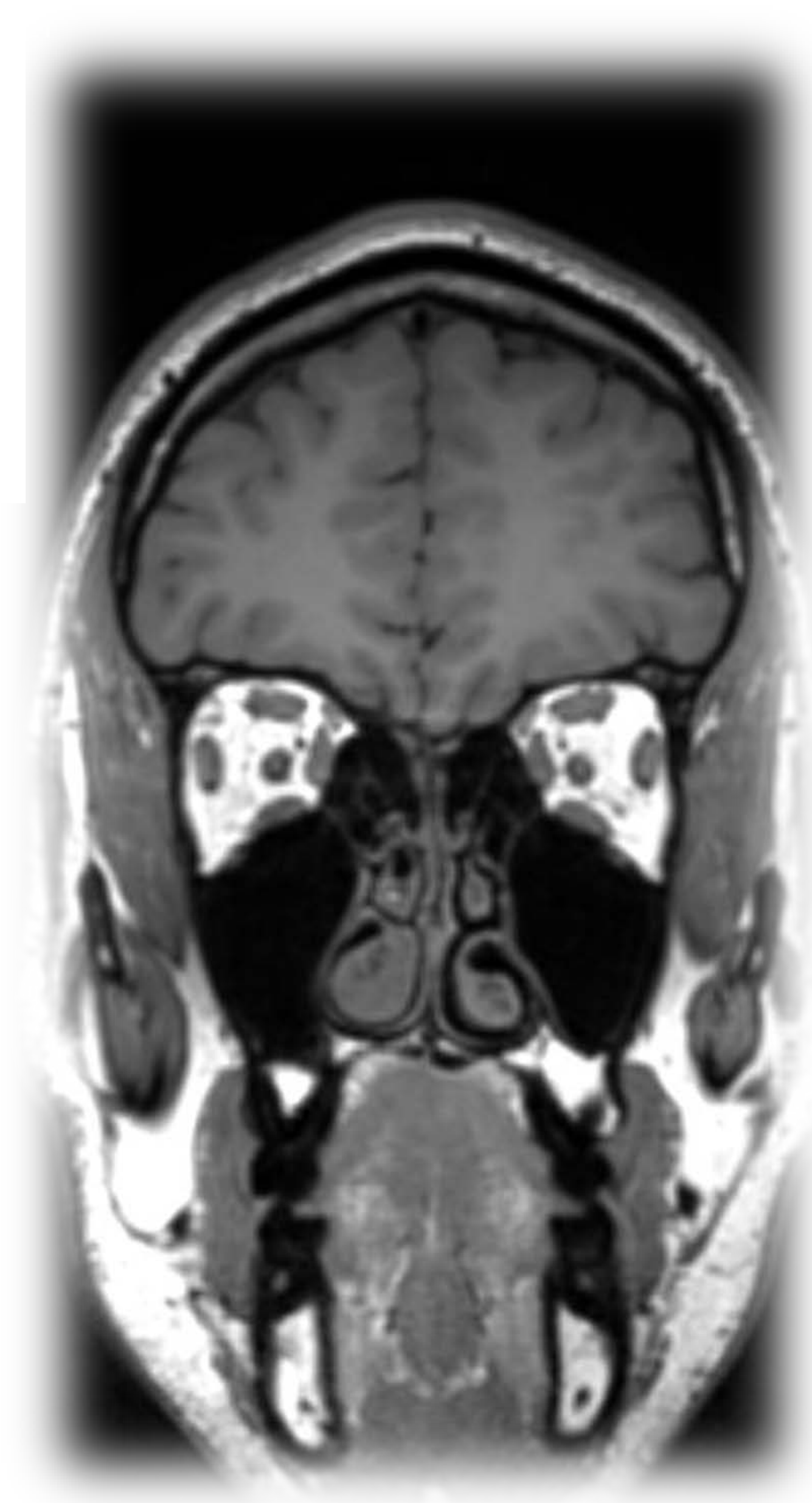

[1] White DE, Nates RJ, Bartley J. Model identifies causes of nasal drying during pressurised breathing. Resp Physiol Neurobiol 2017; 243: 97-100.

\section{Pressure Elicited Change in Airway Surface Liquid Water Supply}

Cellular airway surface liquid (ASL) supply is stimulated by pressure induced tidal breathing stresses. The airway pressure associated with $n$-CPAP causes a $22 \%$ reduction in purinergic sourced ASL water supply [2]

[2] White, D., Nates, R., Bartley, J., 2014. A pilot study of an in-vitro bovine trachea model of the effect of continuous positive airway pressure breathing on airway surface liquid. Biomed. Eng. Online 13, 12

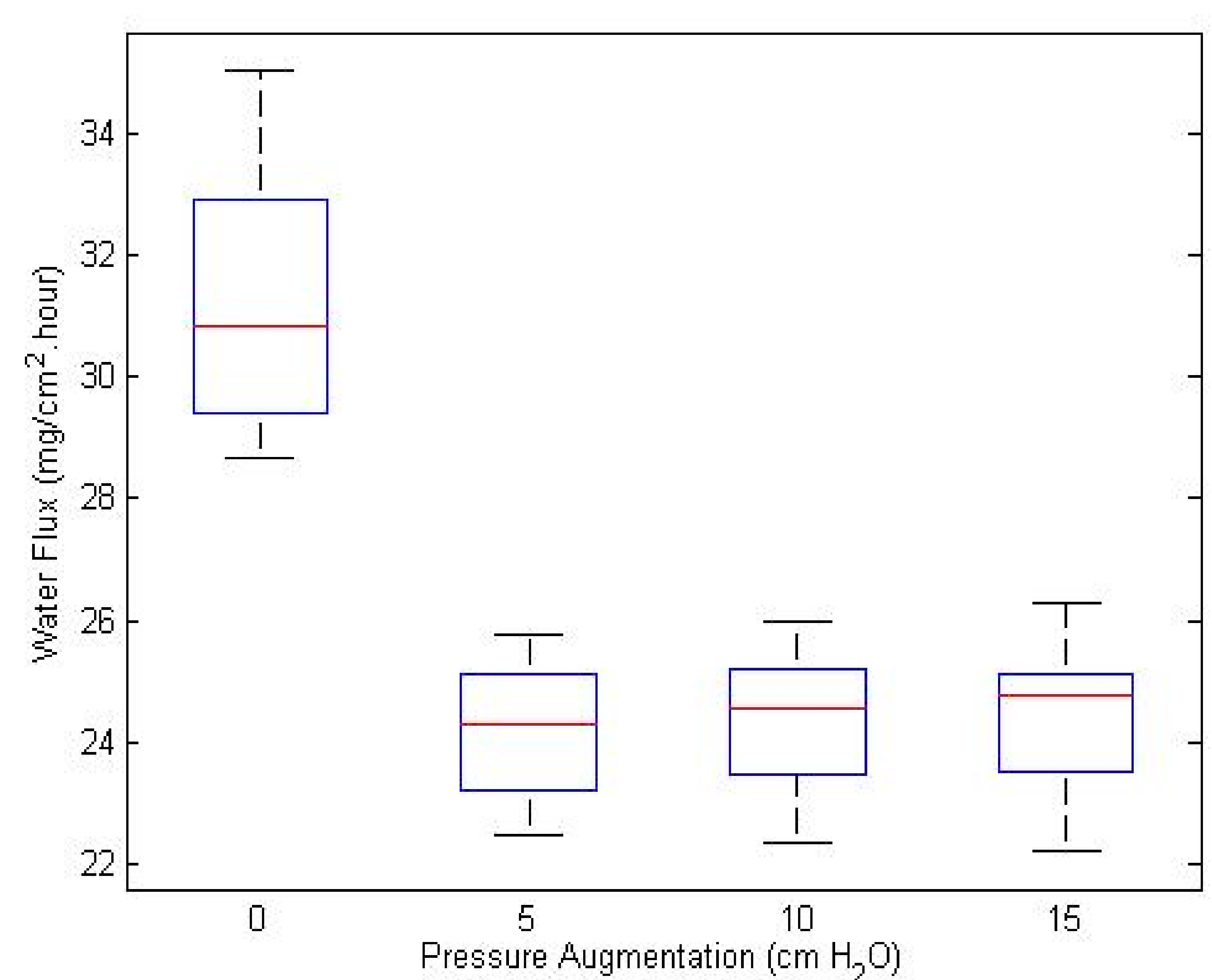

Figure 2: Measured in-vitro bovine trachea ASL water supply during ambient and pressurised breathing.

\section{Inter-Nasal Airflow Apportionment}

Recent investigations in awake patients have found n-CPAP therapy disrupts normal inter-nasal airflow apportionment.

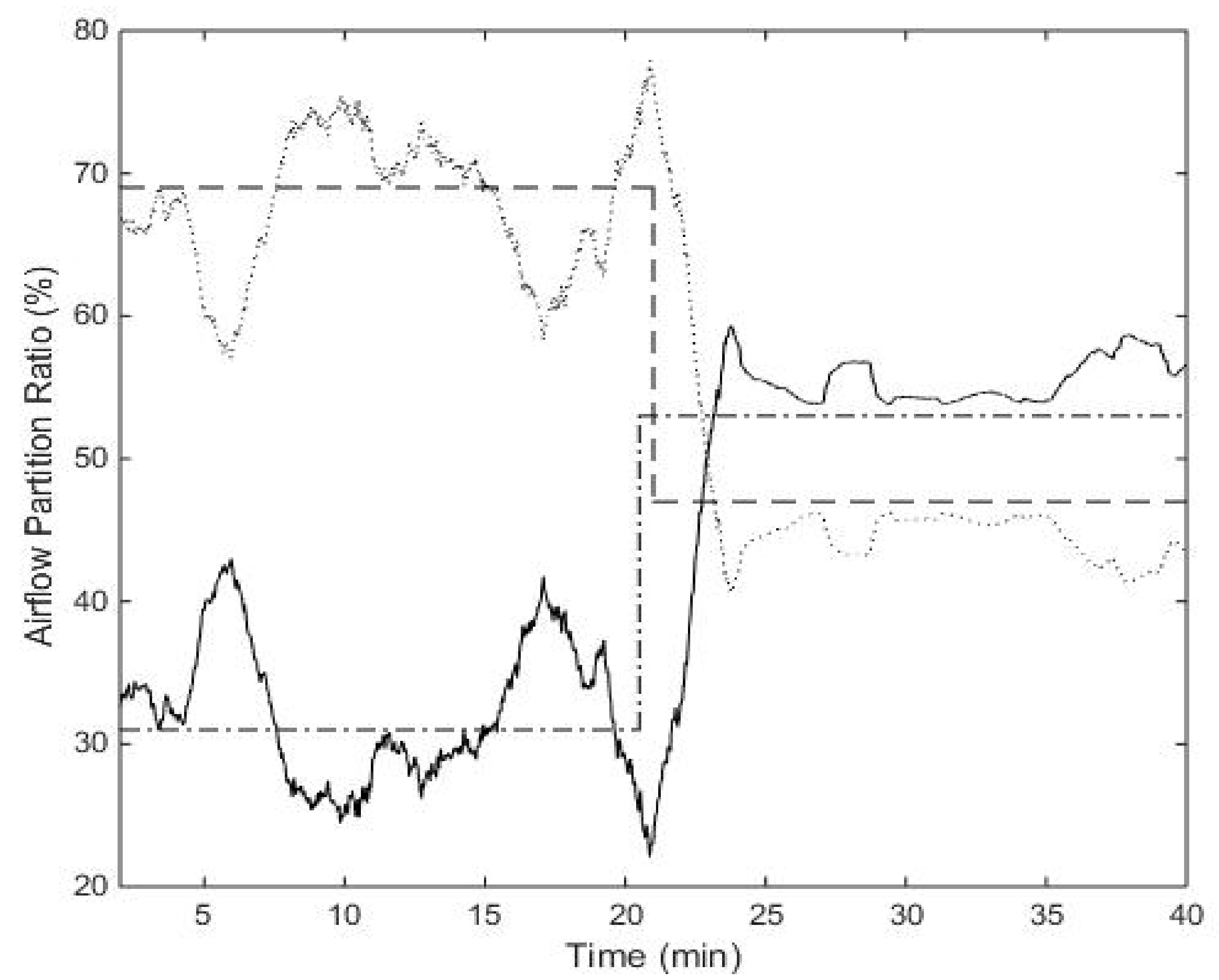

Figure 3: Measured in-vivo and predicted inter-nasal airflow apportionment ratio during the first 21 minutes of ambient and a further 19 minutes during $n$-CPAP breathing at $10 \mathrm{~cm} \mathrm{H} 2 \mathrm{O}$ pressure [3]. Predicted model airflow partition ratios are shown as straight lines as these are based on single MRI image data while measured values fluctuate over time.
= predicted right airway,
= Measured left airway
= predicted right airway,
---- = predicted left airway

[3] White, D.E., Bartley, J., Shakeel, M., Nates, R.J., Hankin, R.K.S., 2016. Nasal airway responses to nasal continuous positive airway pressure breathing: An in-vivo pilot study. J. Biomech. 49, 1887-1890.

\section{Comparison of Nasal Airway Surface Liquid Heights During Ambient and Pressurised Breathing}

During simulated n-CPAP breathing it was found that pressure elicited change in inter-nasal tidal airflow apportionment and the reduction in ASL water supply caused both nasal airways to simultaneously experience severe ASL dehydration along $60-80 \%$ of their anterior length.
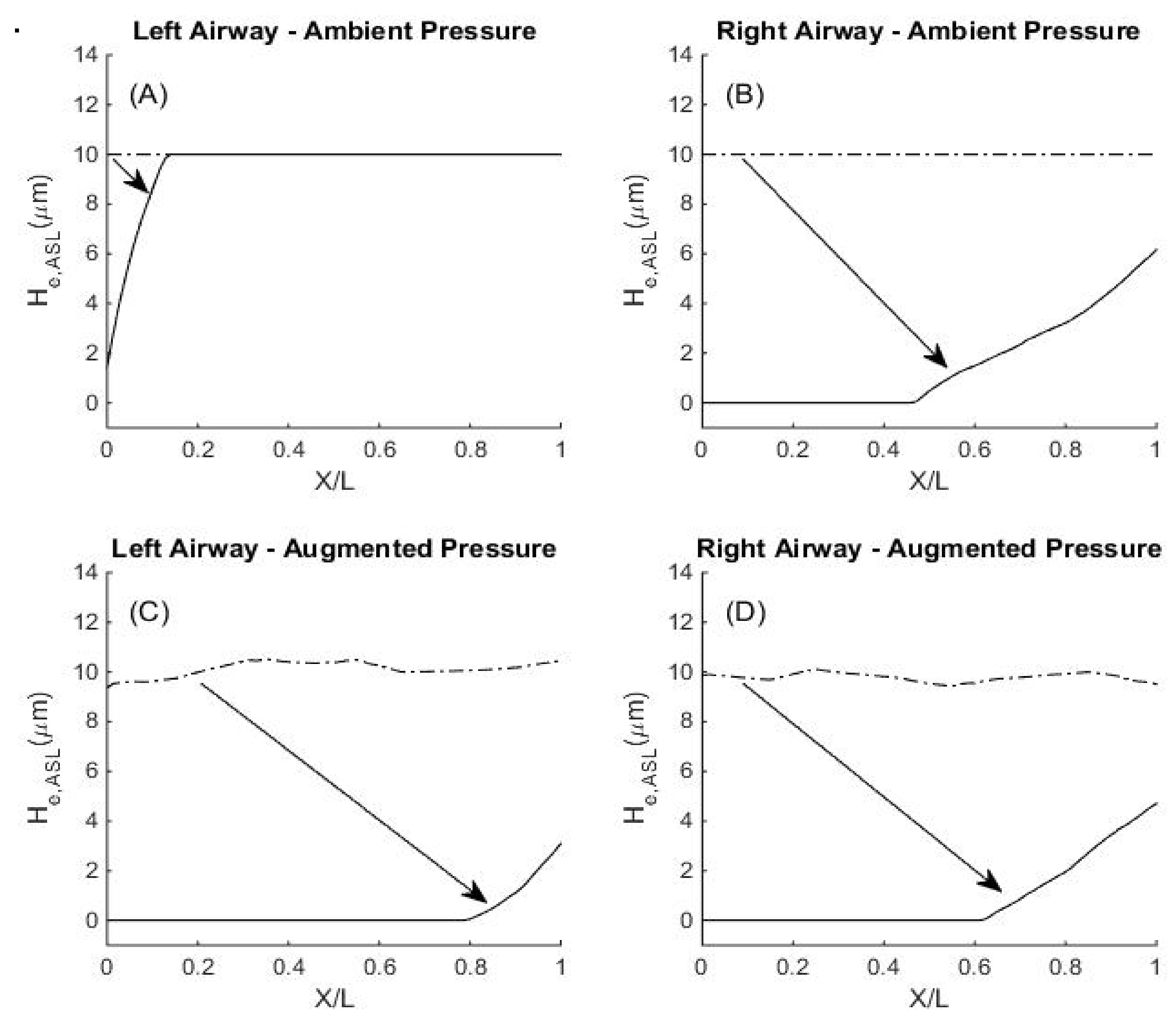

Figure 4: ASL hydration expressed as water equivalent height $(\mathrm{He}, \mathrm{ASL})$ along the nasal airway during simulated ambient air breathing (Figures A \& B) and simulated breathing at $10 \mathrm{~cm} \mathrm{H} 2 \mathrm{O}$ pressure (Figures $\mathrm{C} \& \mathrm{D}$ ) [2]. The arrow in each figure indicates direction of change from initiation of inhalation to maximal change in ASL hydration. Non-dimensional airway position (X/L), defines the ratio of distance from anterior nasal valve to the posterior choanae within the two airways. 